\title{
Mycobacterium Tuberculosis in the 1930 Evacuees from St Kilda, Scotland
}

\section{Peter Stride*}

\section{Consultant Physician and Senior Lecturer, University Of Queensland School Of Medicine, Australia}

*Corresponding author: Peter Stride, Consultant Physician and Senior Lecturer, University of Queensland School of Medicine, MB BS (LOND), FRACP, FRCPEdin, FRCP, D.MED (UQ), Australia

\section{Abstract}

The Covid-19 pandemic of 2020 reminds us that the advent of infectious diseases into a non-immune, though medically sophisticated community is an ever-present threat to life and health from the dawn of recorded history to the current year. There are numerous examples of endemic diseases in one community being introduced into another often remote and isolated non-immune population with disastrous results. However the converse effect of removing a whole yet small isolated community from a remote location and placing them in a more populous setting is less well analysed. Instead of the infection being taken to the vulnerable non-immune, the vulnerable non-immune are taken to the infection. The occurrence of Mycobacterium tuberculosis (MTB) amongst the evacuees from the remote Hebridean island of St Kilda in the decade after they were transported to the Scottish mainland in 1930 is examined

Keywords: St Kilda; Tuberculosis; Addison's Disease; Immunity; Remote communities

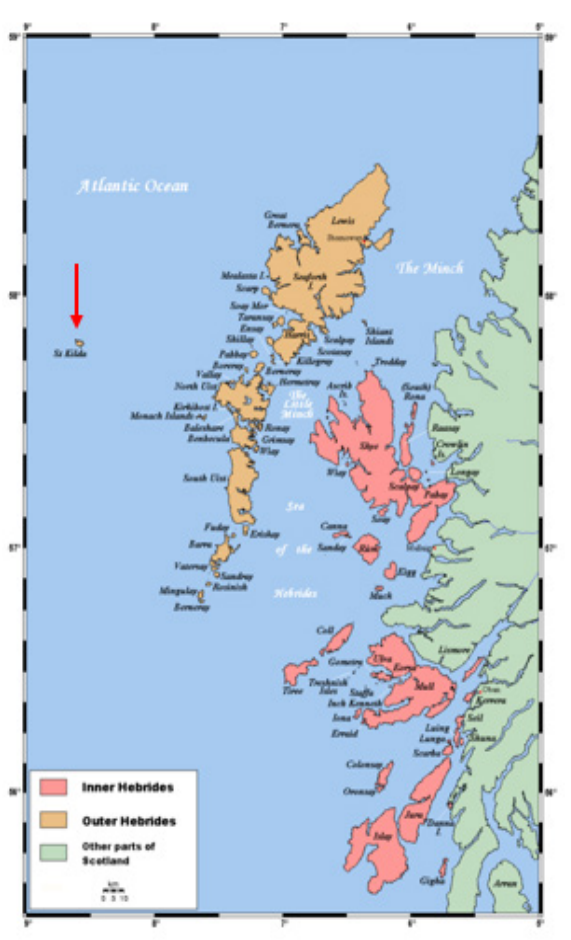

Figure 1: St Kilda, Scotland.

\section{Introduction}

The arrival of infectious diseases in a non-immune, often remote island society frequently causes a catastrophic epidemic. When measles was introduced into Fiji in 1875, for example, forty thousand islanders, a quarter of the population died. Thanks to the measles vaccine Fiji today is free of measles. When the 1918-19 influenza pandemic arrived in Samoa eight thousand people, a fifth of the population died [1]. The Marquesas Islands in French Polynesia lost approximately $80 \%$ of the population over seventy years to four major epidemic diseases, MTB, typhoid, influenza, and smallpox, between 1791 to 1863 [2]. Today, new strains of a common virus can cause a pandemic in a non-immune world. The mutation of a coronavirus apparently from the markets of Wuhan, China has caused nearly half a million deaths world-wide amongst ten million cases within six months in 2020 [3].

\section{St Kilda}

St Kilda, Scotland is a remote Hebridean island in the North Atlantic Ocean nearly four hundred kms north-west of Edinburgh and sixty-four kms north-west from North Uist, the nearest land. It was known to be occupied for several centuries in primitive conditions. The devastating advent of infectious diseases to the isolated non-immune community of St Kilda is well documented. In 1727, an infectious disease, either chickenpox or smallpox killed ninety percent of the adult population [4]. Widespread 
respiratory infections perhaps, rhinovirus, 'the boat cough', followed visits to the island from more populous areas of Scotland [5] (Figure 2).

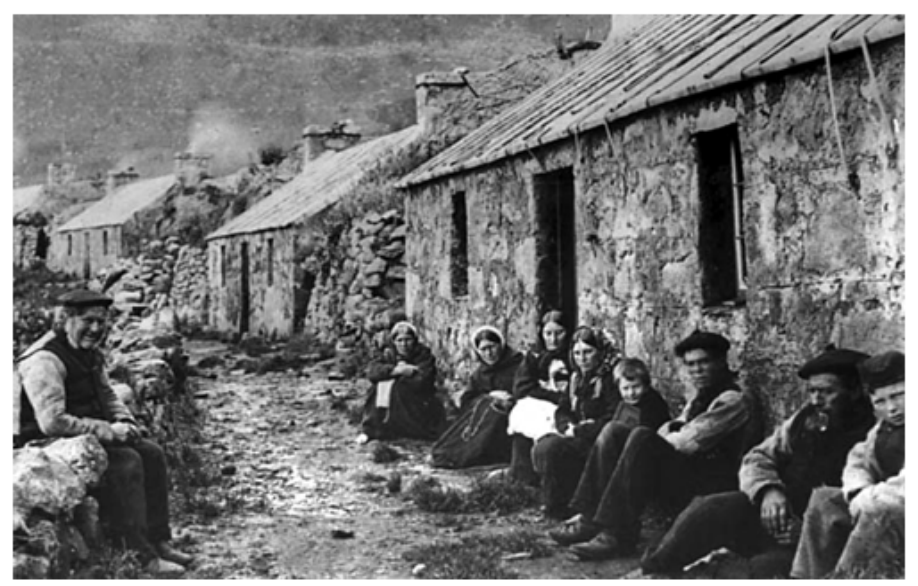

Figure 2: Main Street, St Kilda, 1886.

However the medical effect of removing a whole community from an isolated location and placing them in a more populous setting is less well studied. The occurrence of MTB amongst the evacuees from the remote Hebridean island of St Kilda in the decade after they were transported to the Scottish mainland in 1930 is reviewed. On 29 August 1930, the Harebell embarked the last remaining thirty-six inhabitants of the remote Hebridean island of St Kilda at their request and ferried them initially to the peninsula of Morvern on the west coast of the Scottish mainland, thus sadly but inevitably terminating several centuries of occupation in then unsustainable primitive conditions (Figure 3).

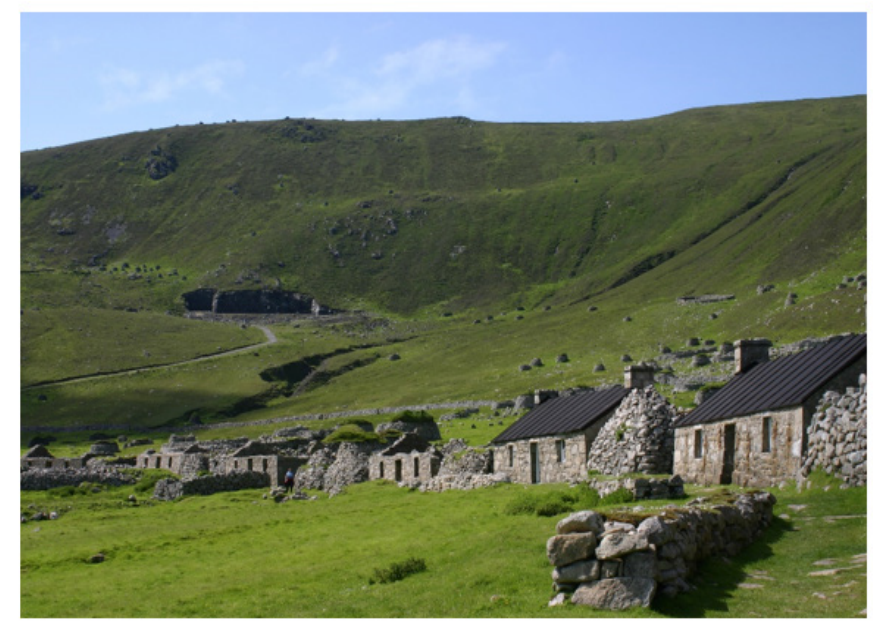

Figure 3: St Kilda today.

Tuberculosis amongst the Evacuated Natives of St Kilda

Death certificates are available from the National Records of Scotland for the eighteen evacuees who died between 1930 and 1970. The remaining eighteen evacuees died between 1970 and 2016. Their individual death certificates with cause of death will become available fifty years after the event. Hopefully, none would have died of MTB after 1970 with the available antibiotic therapy. Five of the thirty-six evacuees (14\%) were known to have died of tuberculosis. Four were siblings between the ages of thirteen to twenty-three. The disease is documented as below on their death certificates. They were all members of a family cohort (McK).

i. The fourth son, the index family case, John McK, died of subacute pulmonary TB, on 7/3/1934 age 13 .

ii. The second son, Donald McK, died of pulmonary TB, one day after pneumothorax therapy, on 20/4/1935 age 23.

iii. The third son, Finlay McK, died of pulmonary TB and tuberculous nephritis on 8/5/1935, age 20 .

iv. The first daughter Rachel McK died of pulmonary TB, on 8/5/1936 age 18, exactly one year after her brother Finlay.

v. The father Norman McK, died of pulmonary and laryngeal TB on 15th December 1941, aged 61

vi. Mrs Ann Mck and the remaining four children survived till the age of at least 62 and died of other causes.

There is one more possible case of MTB which would raise the percent dying of MTB to $17 \%$. A sixth evacuee Ewen McD died on 24/5/37 of Addison's disease and cardiac failure age 42. Tuberculosis was a common cause of Addison's disease at that time. He was not living near the family McK cohort. His death was in the central Glasgow suburb of Hillhead, while the McK family were still living in the west highland peninsula of Morven. A seventh death perhaps due to the evacuation occurred from measles, an infectious disease common on the mainland, but not recorded on St Kilda. One male died ten years after the evacuation with measles, though he was aged 85 with senility and myocarditis also recorded on the death certificate.

\section{Discussion - Tuberculosis in the 1930s Frequency}

A contemporary textbook of pulmonary disease, Diseases of the Chest [6] notes that MTB can be traced in the earliest medical writings and is currently a leading cause of mortality. The death rate from MTB during the second decade of the twentieth century in the town of Framingham, Massachusetts was estimated to be 100 per 100,000 or $0.1 \%$ as opposed to the fourteen - seventeen percent in

Citation: Peter Stride*, Mycobacterium Tuberculosis in the 1930 Evacuees from St Kilda, Scotland. Op Acc J Bio Sci \& Res 5(1)-2020. 
te St Kilda evacuees. Norris notes that white races have acquired immunity to MTB over the centuries, while the African-American and North American Indian races have a high susceptibility. In 1915 MTB was responsible for 35\% of deaths among North American Indians and the death rate in African-Americans in the northern cities of USA was six or seven times as high as the white death rate.

Immunity to MTB depends predominantly upon a complex cascade of innate and adaptive cellular immunity, some components of which are subject to genetic polymorphism. The inhabitants of St Kilda, predominantly inbred for many centuries in an MTB free environment would have had no selection pressure to favour the more active polymorphisms. Testing of humeral immunity is producing mixed results and appears less important than cellular immunity [7].

\section{Diagnosis}

Diagnostic tests in 1930 were similar to those currently employed. The tubercle bacillus had been first identified by Robert Koch in 1882 as an oxygen-dependent organism impervious to gram staining, but stainable and detectable in infected tissue with methylene blue and in sputum with acid-fast stains such as the Ziehl-Neelsen stain. In 1882, Koch stated that currently one death in seven was due to TB. Koch received the Nobel Prize in Medicine in 1905 in recognition of his work [8]. The tuberculin skin reaction named after Charles Mantoux, though developed from earlier work by Koch and von Pirquet, became available in 1907. The accuracy of this test improved as the tuberculin protein was progressively purified, but currently may be replaced by the Gamma Interferon test [9]. Radiology was well established by 1930 as a diagnostic tool for pulmonary tuberculosis, especially when apical cavity formation is visible. Viewing chest $x$-rays was then a radiologist's predominant function. Norris regards it as a confirmatory utility of less importance than clinical features and sputum examination as its specificity and sensitivity are suboptimal.

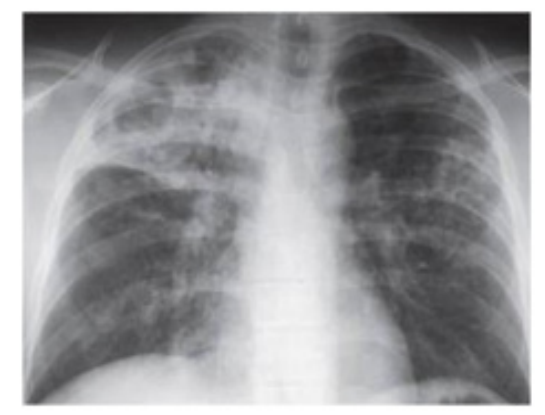

Figure 4: Apical cavity, pulmonary tuberculosis.
Norris suggests its importance is to follow radiological progress over time [6] (Figure 4).

\section{Treatment}

No effective therapy was available in the 1930s. Sanitoria, fresh air, higher altitudes and good food were commonly recommended. Pneumothorax had become a recommended therapy since the observation that sufferers from MTB were more likely to recover following a sword wound to the chest [10]. Other operations included lung resection, pneumo-peritoneum, and phrenic nerve crush [11]. Drug therapy for MTB was developed not long after the St Kilda cohort deaths. Para-amino-salicylic acid was first synthesised in 1902, but its efficacy against M. tuberculosum was not recognised till 1944. It is still useful in combination therapy against drug resistant MTB. Streptomycin was synthesised in 1943 and utilised to treat MTB also in 1944. Isoniazid was first utilized in 1952, ethambutol in 1961, rifampicin in 1968 and pyrazinamide in 1972 [12]. Had the St Kilda cohort been evacuated a decade later they may have then had a curable disease

\section{Addison's Disease and MTB}

The death of one evacuee from Addison's disease raises the possibility of a tuberculous infection of the adrenal glands. Today autoimmune adrenalitis caused by an immune reaction against the enzyme 21-hydroxylase is recognised as the most common cause of Addison's disease, while adrenal tuberculosis is less common. Today, diagnosis of Addison's disease would depend upon hormone assays, imaging and the synacthen stimulation test. In the 1930s it would have depended upon the clinical features of advanced disease. In 1997 Willis found twelve cases of autoimmune disease and ten cases of old tuberculosis among thirty patients with Addison's disease in England [13]. Atrophy, trauma, malignant infiltration, and other infections including meningococcal disease also occur.

Aetiology of Addison's disease however differed in past centuries. In 1855 the first six cases published by Addison were all were diagnosed as caused by tuberculosis [14]. In 1892 Osler wrote that MTB was the most common cause of Addison's disease. His opinion was supported by a high percentage of autopsies revealing thickened caseating adrenal glands and MTB elsewhere in the body, usually the lungs [15]. In 1928 Philpott described fourteen cases of Addison's disease noted in 2550 autopsies, of which seven were due to MTB [16]. Four were due to metastatic carcinoma, one to mycosis fungoides, one to simple atrophy and one to amyloidosis. In 1950, O'Donnell noted MTB as the cause of Addison's in $70 \%$ of 403 autopsy detected

Citation: Peter Stride*, Mycobacterium Tuberculosis in the 1930 Evacuees from St Kilda, Scotland. Op Acc J Bio Sci \& Res 5(1)-2020. 
cases between 1900 and 1920, but as the cause of eight of eighteen (44\% ) cases of Addison's disease in 9,000 autopsies conducted between 1930 and 1950 [17]. There is therefore in the 1930 s a greater than fifty percent chance that $\mathrm{E}$. McD also had M TB as the cause of Addison's disease.

\section{Measles}

Measles, the partial cause of death in one evacuee, caused the death of nineteen of the thirty-six St Kildan migrants en-route for Australia aboard the 'Priscilla' in 1852 , strongly implying a lack of herd immunity to measles on St Kilda [18].

\section{Other Causes of Death}

The other eleven available death certificates documented five deaths from cardiac disease, four with gastro-intestinal diseases and two from central nervous system diseases. The ages at death of these eleven ranged from 48-88 (mean 70), an unremarkable figure for Scotland in the 1950s.

\section{Parallels from Other Countries}

Tuberculosis spreads rapidly and fatally amongst detainees in harsh prison camps such as the Boer prison camps during the South African Boer War, the Uyghur detention centres in China today, and the Nazi concentration camps in which the Jewish population were deliberately exposed to MTB, but this is a different concept from voluntary relocation. An island almost completely isolated from external disease for perhaps sixty-thousand years, though much larger and with a greater population than St Kilda, was Australia prior to the arrival of the British First Fleet in 1788. The advent of smallpox, chickenpox, tuberculosis, pertussis, measles, and syphilis caused a horrendous morbidity and mortality of Australia's first people in Australia. There are two examples of death from probable MTB caused by removing Indigenous men from Australia and taking them to England in the eighteenth and nineteenth centuries, similar to the events occurring to St Kilda's evacuees.

Governor Arthur Phillip, on his retirement from Sydney, took two Indigenous males with him back to England. One of them, Yemmurrawannie, died in England of a respiratory infection which was thought to be MTB while the other, Bennelong returned safely to Australia. In 1868 an Australian indigenous team of fourteen men sailed to England for a cricket tour. During five months in UK they played forty-seven games, winning fourteen, losing fourteen and drawing the remainder. Some displayed remarkable skills, particularly Johnny Mullagh who scored 1,698 runs and took 245 wickets. George Tarrant, a leading English fast bowler said of Mullagh, "I have never bowled to a better batsman." After cricket games, the indigenous players displayed their skills at throwing boomerangs and spears. However in spite of this athleticism, one of their team, King Cole, arguably the side's best fielder, had been taken ill with a respiratory condition and died about six weeks after arriving in England of suspected tuberculosis. Three others died within five years of returning from England though the cause are unknown [19].

\section{Conclusion}

The evacuees from the islands of St Kilda, Scotland were at an increased risk of death from common infectious disease in the decade after their evacuation in 1930. One male died with measles. Five members of a family cohort died from MTB in Morven, and a relative of heart failure and possible adrenal MTB in Glasgow as a result of being introduced into a wider population on mainland Scotland from the isolated remote non-immune community of St Kilda in the Hebrides when it was evacuated in 1930, in the decade before the development of anti-tubercular drug therapy

\section{Acknowledgement}

I am indebted to the late Dr Francis Esmond Browne OAM, MB BS (Melb), long term solo-GP to Lord Howe Island for his copy of Norris. He would have obtained this text in 1930 while honorary medical officer at Swan Hill District Hospital. In 'retirement' he worked near Port Macquarie till aged 90 . He died aged 98 on 9/8/1997.

\section{References}

1. Shanks D (2016) Pacific Island Societies Destabilised by Infectious Diseases History. 24 (4): 71-74.

2. Martin P, Combes C (1996) Emerging Infectious Diseases, and the Depopulation of French Polynesia in the 19th Century. Emerging Infectious Diseases 2(4): 359-361.

3. www.covid19data.com viewed 28.6.2020

4. Stride P (2009) The St Kilda Epidemic of 1727, Smallpox or Chickenpox J R Coll. Physicians Edinb 39(3): 276-279.

5. Stride $P$ (2008) The St Kilda boat cough under the microscope J R Coll. Physicians Edinb 38: 272-279.

6. Norris G, Landis H (1929) Diseases of the Chest, W.B.Saunders, Philadelphia.

7. Moller M, Kinnear C, Orlova M (2018) Genetic Resistance to Mycobacterium tuberculosis Infection and Disease. Front Immunol 9: 2219.

8. Koch R, Brock T, E Fred (1982) The Etiology of Tuberculosis Reviews of Infectious Diseases 4(6): 1270-1274.

9. Pottumarthy S, Morris A, Harrison A, Wells V (1999) Evaluation of the Tuberculin Gamma Interferon Assay: Potential to Replace the Mantoux Skin Test. J Clin Microbiol 37: 3229-3232.

10. Kumar R, Moodley L (2014) Resurgence of therapeutically destitute tuberculosis: amalgamation of old and newer techniques J Thorac Dis 6(3): 196-201.

Citation: Peter Stride*, Mycobacterium Tuberculosis in the 1930 Evacuees from St Kilda, Scotland. Op Acc J Bio Sci \& Res 5(1)-2020. 
11. Murray J, Schraufnagel D, Hopewell P (2015) Treatment of Tuberculosis A Historical Perspective. Ann Am Thorac Soc 12 (12): 1749-1759.

12. Iseman M (2002) Tuberculosis therapy: past, present, and future. Euro Resp J 20: $87 \mathrm{~s}-94 \mathrm{~s}$.

13. Willis A, Vince $F$ (1997) The prevalence of Addison's disease in Coventry, Postgrad Med J UK, 73: 286-288.

14. Addison T (1855) On the Constitutional and Local Effects of Disease of the Suprarenal Capsules London: Samuel Highley.

15. Osler W (1982) The principles and practice of medicine New York D. Appleton and Co, USA.

16. Philpott N (1928) Addison's Disease in association with amyloidosis. Ann Int Med 1(8): 613-620.

17. O'Donnell W (1950) Changing pathogenesis of Addison's disease with special reference to Amyloidosis. Arch Intern Med (Chic) 86(2): 266-279.

18. Richards E (1992) St Kilda and Australia: Emigrants at Peril, 1852-3 The Scottish Historical Review 71(191/192) : 129-155.

19. Mulvaney J (1988) Aboriginal Australians abroad 1606-1875. Aboriginal Hist J 12: 40-47.

*Corresponding author: Peter Stride, Email: pjostride@gmail.com

Next Submission with BGSR follows:

- Rapid Peer Review

- Reprints for Original Copy

- E-Prints Availability

- Below URL for auxiliary Submission Link: https://biogenericpublishers.com/submit-manuscript/ 